\title{
Working Together: Integrating Computational Modeling Approaches to Investigate Complex Phenomena
}

\author{
Tom Bielik $^{1}\left[\right.$ Ehud Fonio ${ }^{2} \cdot$ Ofer Feinerman $^{2} \cdot$ Ravit Golan Duncan $^{3} \cdot$ Sharona T. Levy $^{4}$
}

Accepted: 23 September 2020 / Published online: 22 October 2020

(c) The Author(s) 2020

\begin{abstract}
Complex systems are made up of many entities, whose interactions emerge into distinct collective patterns. Computational modeling platforms can provide a powerful means to investigate emergent phenomena in complex systems. Some research has been carried out in recent years about promoting students' modeling practices, specifically using technologically advanced tools and approaches that allow students to create, manipulate, and test computational models. However, not much research had been carried out on the integration of several modeling approaches when investigating complex phenomena. In this paper, we describe the design principles used to develop a middle school unit about ants' collective behavior that integrates three modeling approaches: conceptual drawn models, agent-based models, and system dynamics models. We provide results from an initial implementation of an 8th grade curricular unit, indicating that students engaged with several aspects of the modeling practice. Students' conceptual knowledge about ant pheromone communication increased following learning the unit. We also found gains in students' metamodeling knowledge about models as tools for investigating phenomena. We discuss the affordances and challenges of engaging students with several modeling approaches in science classroom.
\end{abstract}

\section{Introduction}

Science is about explaining the natural world. These explanations often come in the form of models and theories that are grounded in evidence (Harrison and Treagust, 2000; Lehrer and Schauble 2006). In this sense, science education is not just about learning concepts. It is just as much about learning to construct models, explain, argue, and reason using evidence and models (Penner, 2000). Developing and using models are key scientific and engineering practices (National Research Council [NRC], 2012). Models serve to explain and predict phenomena, and scientists use evidence to support or refute alternative models. Given that modeling plays such a central goal of science, it received much attention in science education. Students are expected to construct, use, evaluate, and revise models to make

Ravit Golan Duncan is a Visiting Faculty Program Fellow at the Weizmann Institute of Science, Rehovot, Israel.

Tom Bielik

tom.bielik@fu-berlin.de; tombielik@gmail.com

Freie Universität, Berlin, Germany

2 Weizmann Institute of Science, Rehovot, Israel

3 Rutgers University, New Brunswick, NJ, USA

4 University of Haifa, Haifa, Israel sense of phenomena or to solve problems. However, most students are not provided with meaningful opportunities to engage in this practice (Schwarz et al. 2009).

Students' modeling competence is typically viewed in two dimensions: modeling metaknowledge and the modeling practices (create, use, compare, validate, revise) (Chiu and Lin, 2019; Nicolaou and Constantinou, 2014; Nielsen and Nielsen, 2019). In recent years, metamodeling knowledge has moved to the forefront and it was found to be central to students' ability to learn with models (Rinehart et al., 2016; Krell and Krüger, 2017; Schwarz et al. 2009).

Different modeling approaches highlight distinct features of phenomena and systems, and scientists have used multiple types of models to study the same phenomenon. Wilkerson et al., (2018) described two aspects of engagement with models: epistemic forms (model elements, representational structures) and epistemic games (modeling strategies), which can be found in different modeling approaches.

In most research carried out on developing students' modeling practice, students usually engage with one modeling approach (e.g., diagrams, animations, agent-based modeling, or system dynamics). This does not provide students with opportunities to develop understandings of multiple types of models that could be used to investigate different features of the same phenomenon and that different models can 
have distinct advantages and disadvantages (Schwarz et al., 2009). As a result, there have been calls for combining multiple modeling approaches, such as agent-based modeling and system dynamics (Eilam and Reisfeld, 2017; Guerrero et al., 2016; Stroup and Wilensky, 2014; Wilkerson-Jerde, et al., 2015).

Little is known about designing curricular materials that combine multiple modeling approaches and about how students make sense of the similarities and differences of various approaches as well as their affordances and constraints. Therefore, this study aims to present a design case of a curricular middle school unit that integrates several modeling approaches. In this unit, students constructed conceptual models and used two computational modeling tools to make sense of the familiar, yet complex, phenomenon of ants' trail formation, as an example of collective behavior. We discuss how students used the different modeling approaches and the challenges and successes students encountered when using the different modeling tools during a short intervention.

Our research questions were the following: (i) How did students engage with the different modeling approaches integrated in the unit? and (ii) What were the changes in students' conceptual understanding and metamodeling knowledge following learning the unit?

\section{Literature Review}

Models consist of components and relationships, and they are used by scientists and engineers for representing systems and explaining phenomena (Harrison and Treagust, 2000; Schwarz et al. 2009). A Framework of K-12 Science Education (National Research Council [NRC], 2012) defines the modeling as developing, revising, using, and evaluating models to predict phenomena and to describe unobservable mechanisms. The modeling practice is viewed as critical for advancements in science knowledge and important for students to make sense of phenomena and share their ideas (Passmore, et al., 2014).

In using the term conceptual models, we refer to mental models that students externalize through various forms of representations, including box and arrow, drawings and diagrams, and written descriptions of mechanisms (Gentner and Stevens, 1983; Johnson-Laird, 1994). While Nersessian (1992) has used the term to denote expert generated models, we are broadening this conceptualization to include models that students generate that are likely not scientifically accurate, are incomplete, and are not necessarily mathematical (Schwarz et al., 2009). Conceptual models make students' ideas visible to themselves and to others and thus can serve as fodder for discussion about competing explanations and the sorts of evidence needed to decide which model best explains the phenomenon Pluta et al.,(2011)
Complexity approaches to modeling systems have come into the limelight in several different domains of science (social, natural, and more) and have entered the practice of education. Agent-based modeling (ABM) is one of the main forms of expressing this approach. ABM is based on the idea that a system can be represented as many entities that operate according to a small set of simple rules. For example, ant convoys can be seen as resulting from interactions between single ants, food sources, and pheromones. Examples of interaction rules include the following: an ant who finds food goes home (nest) while dropping pheromones and foraging ants with no food head for the strongest scent. Emergence is a central concept associated with complexity and is the process by which the actions and interactions of the system's entities emerge into global patterns (Bar-Yam, 1997). The actions of many individual ants can reach a critical mass which results in a path of pooled scent and the familiar ant trails. In learning to reason through an ABM approach, students notice the main entities in the system, define their properties and actions, and lay out the rules of interactions between the different kinds of entities.

Another common approach of modeling is system dynamics (SD). The SD approach focuses on the complex, timebased, nonlinear characteristics of a phenomenon, where the rates at which different processes take place rise and fall as a result of feedback loops (Forrester, 1994). This includes consideration of the boundaries and components of the system, interactions between components in the system and between different systems, and emergent properties and behavior of the system (Russ et al., 2008). The outcomes of SD models can be counterintuitive, and it is difficult to know a priori which components of the system will have significant impact on the model behavior. Engaging in the modeling practice through SD can provide a scaffold to help students develop a system thinking perspective (Zimmernman, 2007). For example, SD models can demonstrate how rising temperature can affect the rate of ants' food transfer to the nest, as the high temperature causes the pheromones to evaporate faster and thereby make the formation of the ant trail take more time. Engaging in the modeling practice through SD can support students' system thinking perspective.

Few studies compared between different modeling approaches. Thompson and Reimann (2010) studied the students' exploration of ABM and SD models, finding distinct features describing each of these. Several studies focused on the effect of integrating multiple modeling tools on students' learning. Stroup and Wilensky (2014) focused on how ABM and SD forms of reasoning may enrich each other and how these perspectives may be developed in learning mathematics and science, naming it "embedded complementarity." Wilkerson-Jerde et al. (2015) explored students' engagement when modeling using diagrams, animations, and computational models, finding two distinct 
modeling cycles: "messing about" and "digging in." Eilam and Reisfeld (2017) integrated both SD and ABM modeling approaches in a 9th grade simulation-based full semester curriculum, identifying several students' complex systems thinking cognitive learning aspects and finding improvement in students' system thinking following learning the curriculum.

The development of students' metamodeling knowledge is comparatively well studied, focusing on students' knowledge about the nature, purpose, and function of scientific models (Pluta et al., 2011; Gilbert, 2004; Gobert and Pallant, 2004; Krell and Krüger, 2017; Schwarz and White, 2005). Grosslight et al., (1991) established a classification of students' conceptual understanding of the nature of models, ranging from lower level of considering models as a copy of reality to high level of perceiving models as tools to test and evaluate ideas about natural phenomena. Schwarz, et al., (2009) defined metamodeling knowledge as the understanding of the nature of models, the purpose of modeling, as well as the criteria used to evaluate models. Louca and Zacharia (2012) emphasized the need to investigate the specific relationship between modeling metaknowledge and how people engage in the modeling practice as one pending issue for science education: "One of the most pressing needs for future research is to study [...] the relationship between explicit knowledge concerning the nature of science and the process of modeling, with the ways in which students engage in model creation and revision" (p. 486). In this study, we further investigate the development of students' metamodeling knowledge as they engage in several modeling approaches. This contributes to the existing literature, as not enough is known about the possible contribution of integrating modeling approaches to students' metamodeling knowledge.

Computational modeling tools can be particularly meaningful for students' learning, as they provide them with an opportunity to explain and predict complex dynamic relationships and to visualize abstract concepts (Bielik, et al., 2018; Crawford and Cullin, 2004; Louca and Zacharia, 2012; Sins et al., 2009). For example, Bielik, et., (2018) found that engaging middle school students with a computational modeling tool promoted their abilities to develop high level models in both complexity and quality dimensions in the context of molecular processes related to water quality.

\section{Design and Instructional Context}

\section{Design Principles}

Based on the literature review presented above and the design framework for supporting students' inquiry when using computer software (Quintana et al., 2004), we conceived several design principles for the development of a middle school curricular unit. The three main design principles that guided the development of the unit were:

- Engagement with several modeling approaches-students have meaningful opportunities to engage with several modeling approaches integrated in the unit, including both pictorial representations and computational modeling tools, to investigate different aspects of a complex phenomenon. As we have noted, understanding the plurality of modeling approaches is important, yet underemphasized and under studied aspect of modeling practice (Stroup and Wilensky, 2014).

- Explicit consideration of affordances and constraints of each modeling approach and their integration-students' engagement with the different modeling approaches should be accompanied by explicit consideration of the affordances and constraints of each modeling approach, together with a focus on the complementary aspects of using different modeling approaches when investigating the same phenomenon. Expecting students to develop explicit metaunderstandings from mere engagement with the practice is not effective (Berland et al., 2016). Therefore, to support students' metaunderstandings, students explicitly engage in discussion about it.

- Hourglass modeling sequence-following the introduction of the unit's driving question and anchoring phenomenon, students start building initial models that represent their explanations of the phenomenon. After this, students focus on one plausible model by engaging in an in-depth exploration of its mechanism. Students conclude the unit by engaging with models that allows them to explore new factors that may influence the investigated system, thereby providing them with an opportunity to ask new questions that can lead to further investigation.

\section{Investigated Phenomena: Ants' Pheromone Communication}

Ants demonstrate one of the most intriguing natural complex system and social network. In one nest, thousands of ants continuously collaborate to forage for food and protect the nest. This requires highly evolved communication methods that should be simple and effective across space and time. Ants do not use a centralized communication system. Information is transferred mostly using chemical signals called pheromones. Each ant can release pheromones to alert other ants from approaching dangers or to recruit ants to a food source. When enough pheromones are continuously released by ants, a continuous trail is formed and sustained by ants collecting food to the nest (David Morgan, 2009; Dussutour et al., 2005). This is an example of a phenomenon emerging from 
the collective participating agents. Ants' collaborative behavior and chemical communication when forming the trail is widely studied, providing many theoretical and practical models that are used to solve data transfer problems.

Based on our experience, we knew that students have most likely encountered ant trails in their everyday life and that this would be a relevant and familiar phenomenon that students can readily explain. Our collaborating teacher also believed that this will be an interesting, challenging, and motivating context for student investigations. The phenomenon of ants' pheromone communication was found to be suitable for Israeli middle school students, as it addresses the topics of animal communication in the environment and function and processes in biological systems (Israeli Ministry of Education, 2016).

\section{Unit Design and Enactment}

We developed a curricular unit focusing on the phenomena of ant behavior when foraging for food. The unit included three main lessons. In the first lesson, student groups constructed, drew, presented, and discussed initial conceptual models describing the formation of the ant trails (Fig. 1). In the second lesson, students engaged with the ABM approach. In this lesson, students used an adapted version of the NetLogo ant simulation (Wilensky, 1997, 1999), which supports selecting the underlying rules, which they had come up with
Fig. 1 Examples of student groups' drawn models during lesson 1 to explain the formation of ants' food foraging trails. a Model of an ant recruiting other ants by transmitting signals from the food source. This drawing includes a legend and suggested experiment to test the hypothesis. b Model of ants following each other on the pheromone trail to the food source. Title written in this drawing is 'Ants following the smell'

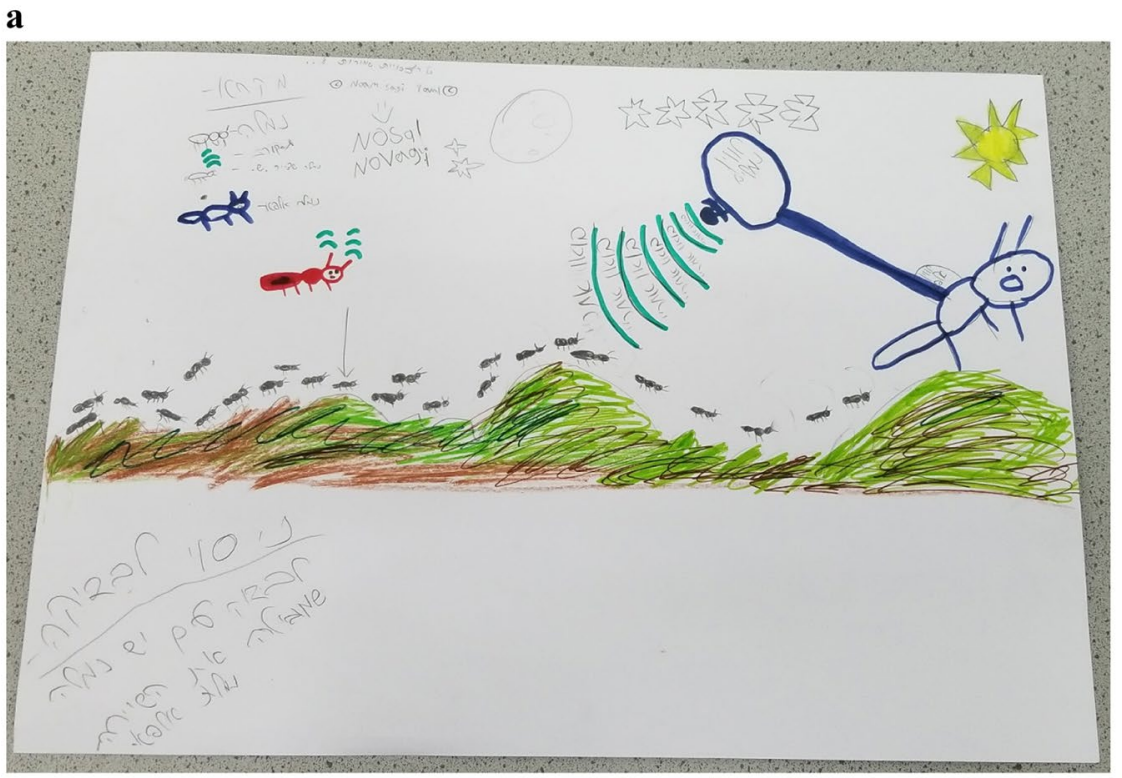

b

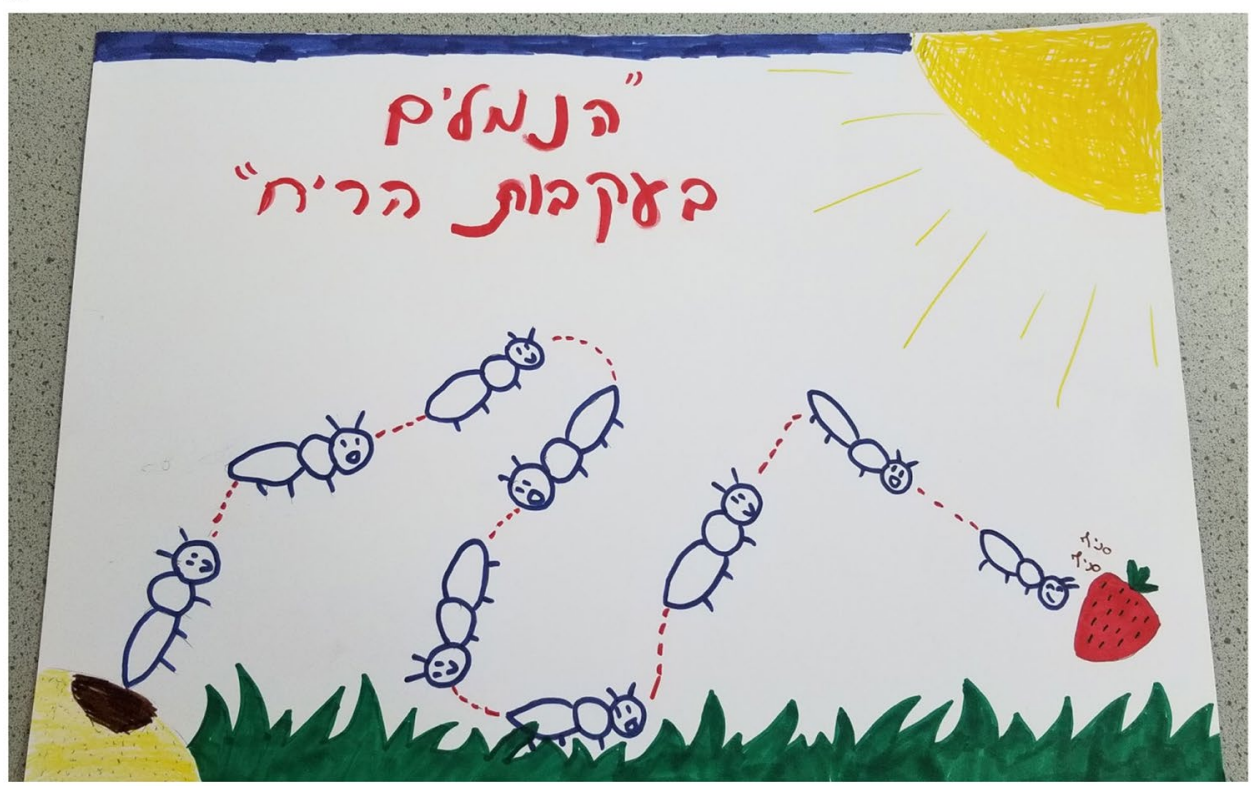


in the first lesson. The students investigated the variables that may affect the efficiency of ant trails when foraging for food (Fig. 2. In the third lesson, students engaged with the SD approach, using SageModeler computational modeling tool (Damelin, et al., 2017; Bielik, et al., 2019) to construct models in which they explored some of the variables affecting the rate of transferring food to the nest by the ants they had encountered in the second part (Fig. 3). At the time of the unit enactment, we could not find ants in the school's surroundings. Instead, we used high-definition movie clips of ants, and the ABM computational model provided a more realistic aspect to explore the formation of ant trails. Detailed description of the lessons and the design principles can be found in the Appendix. The sequence of lessons and expected timeline is provided in Table 1.

The unit was enacted in one 8th grade class. The class's science teacher, Dina (pseudonym), was an experienced middle school science teacher with over 20 years of science teaching experience in both middle and high school life sciences. The authors had several meetings with the teacher to present the unit. Dina made several suggestions to the planned lessons that helped the authors to revise the unit to better fit the class. Since the teacher had no experience with the computational modeling tools, the authors taught some of the lessons, with the support of the teacher.

\section{Materials and Methods}

This is a qualitative study that includes methods used to explore students' models and modeling knowledge and their learning during the enactment of the curricular unit. Some of the presented data is qualitative. However, due to the relatively small data sample, we did not perform any statistical analysis beyond the quantitative representation of the results. Research methods, data sources, and analysis are described below.

\section{Participants}

The unit was enacted in a class of 26 8th grade students (16 females/10 males) from a suburban middle school located in the south of Israel with students of average socioeconomic level. Students in the class were mostly with high learning

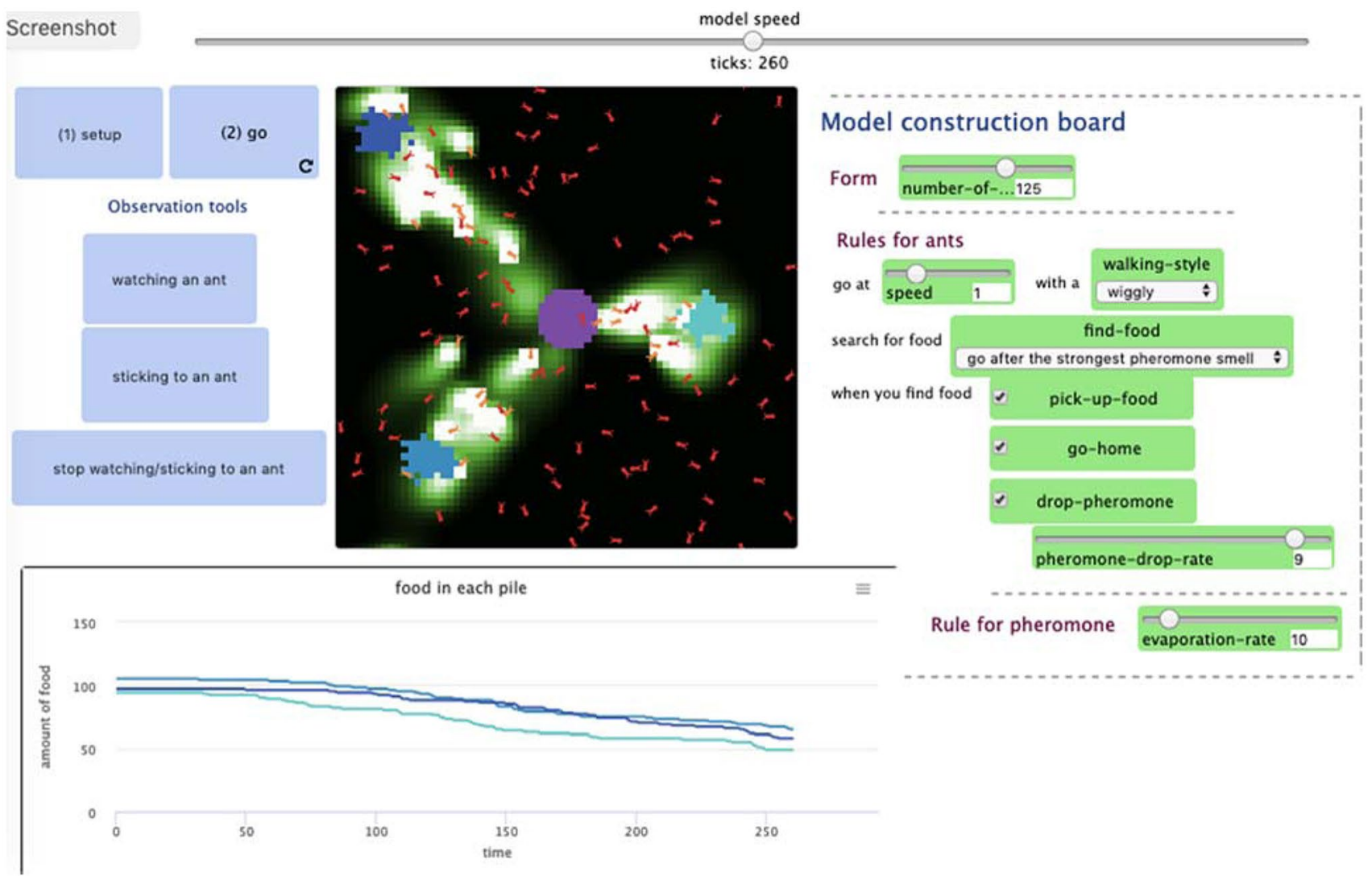

Fig. 2 Screenshot of the NetLogo ant trail activity. In the world simulation box: Red dots represent ants, purple central circle represents ants' nest, blue dots represent three food sources, and bright green areas represent ants' released pheromone trail once food is found and taken to the nest 
Fig. 3 Initial SageModeler model provided to students. Initial model includes two collector variables (amount of food in environment and amount of food in the nest) connected with a valve representing the rate of food transfer from the environment to the nest. Model also includes three variables not connected to the main model: ant speed, number of ants, and pheromone evaporation rate. Model also includes an empty model question/goal box

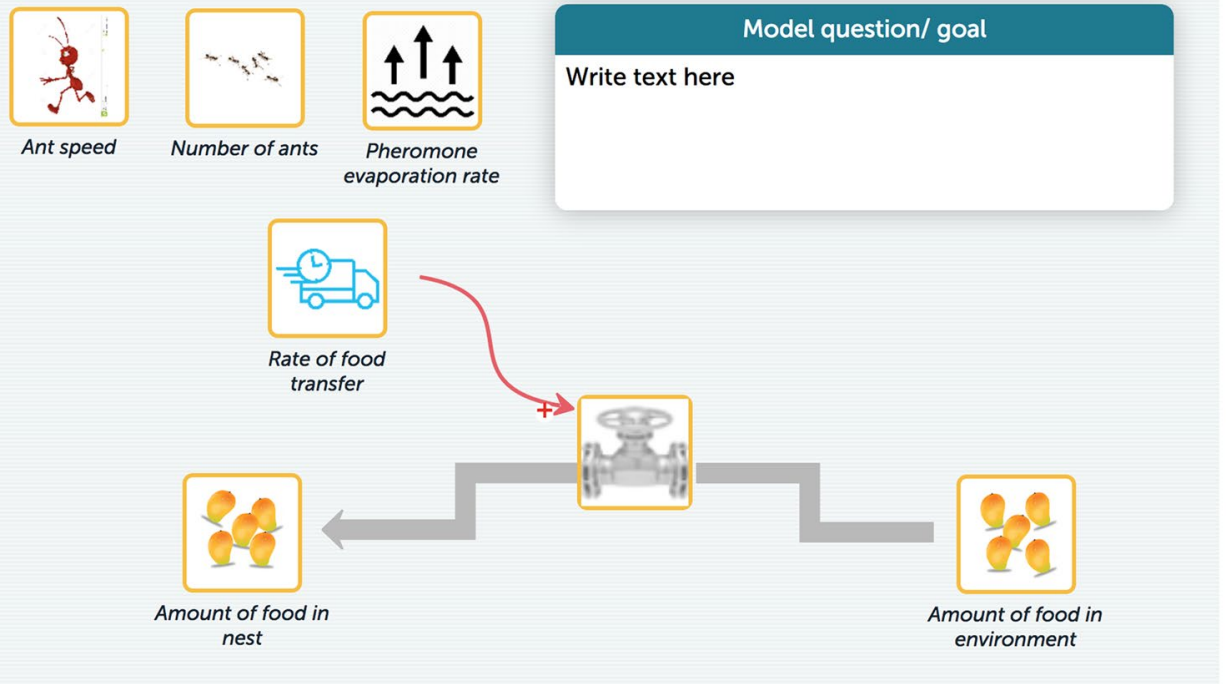

competencies, as they were all in a class of advanced academic achievement program. Based on teacher information, the students in this class learned about models in science lessons earlier in the school year, mostly using particle nature of matter model to explain and predict phenomena. However, no explicit teaching about modeling or the nature of models had been carried out by the teacher.

\section{Tools, Methods, and Analysis}

\section{ABM Activity}

An adaptation of the NetLogo ant model replaced the interface of the original model with a sequence of screens in which widgets were used to select and construct the rules in the model: from the number of ants, through their walking style, all the way to the full set of interactions among the ants, and with the pheromone drops, within their environment. Printed worksheets provided step-by-step instructions for using the models. As the activity progressed, more choices of code were provided, and more combinations of these blocks were made possible.

In the beginning of the ABM activity, students divided into groups of 2-3 students of their own choice. Six groups filled out the worksheets. The worksheet required students to answer questions that guided their investigation and demonstrated their understanding (e.g., "Describe what is happening in the model"), predictive questions for the simulation outcome (e.g., "What do you think will happen if the food transfer rate if the ants will walk faster?"), and questions about the conclusions from running the model (e.g., "What can you conclude from working with this model? Write at least three conclusions."). The worksheets were analyzed for emerging themes by one of the authors.

\section{SD Modeling Activity}

In the beginning of the SD activity, students divided into groups of 2-3 students of their own choice. Each group worked on a computer to develop their model. Students' produced links to their final models which were collected for analysis. All text written in the models were translated from Hebrew to English by the authors. Models were analyzed to investigate the possible development of students' modeling practice using the following criteria:

a Understanding the purpose of the model or the question that the model addresses-we examined students' written text in the box that asks for the model question/goal.

b Using the correct and relevant variables and relationships-we examined the variables and the relationships between them, as defined by the students.

c Using sophisticated explanations for defining the relationships between variables-to explore this aspect, students' written text in the explanation box for each relationship between variables in the model was evaluated. Explanations varied from no written explanation or a nonrelevant response to full explanations that included evidence and justification, such as empirical data or prior knowledge.

The evaluation of students' explanations was independently performed by two of the authors, and full consensus was achieved.

\section{Lesson Recordings and Observation Notes}

All lessons were audio recorded. In addition, observational notes were recorded by the authors. Recordings and 


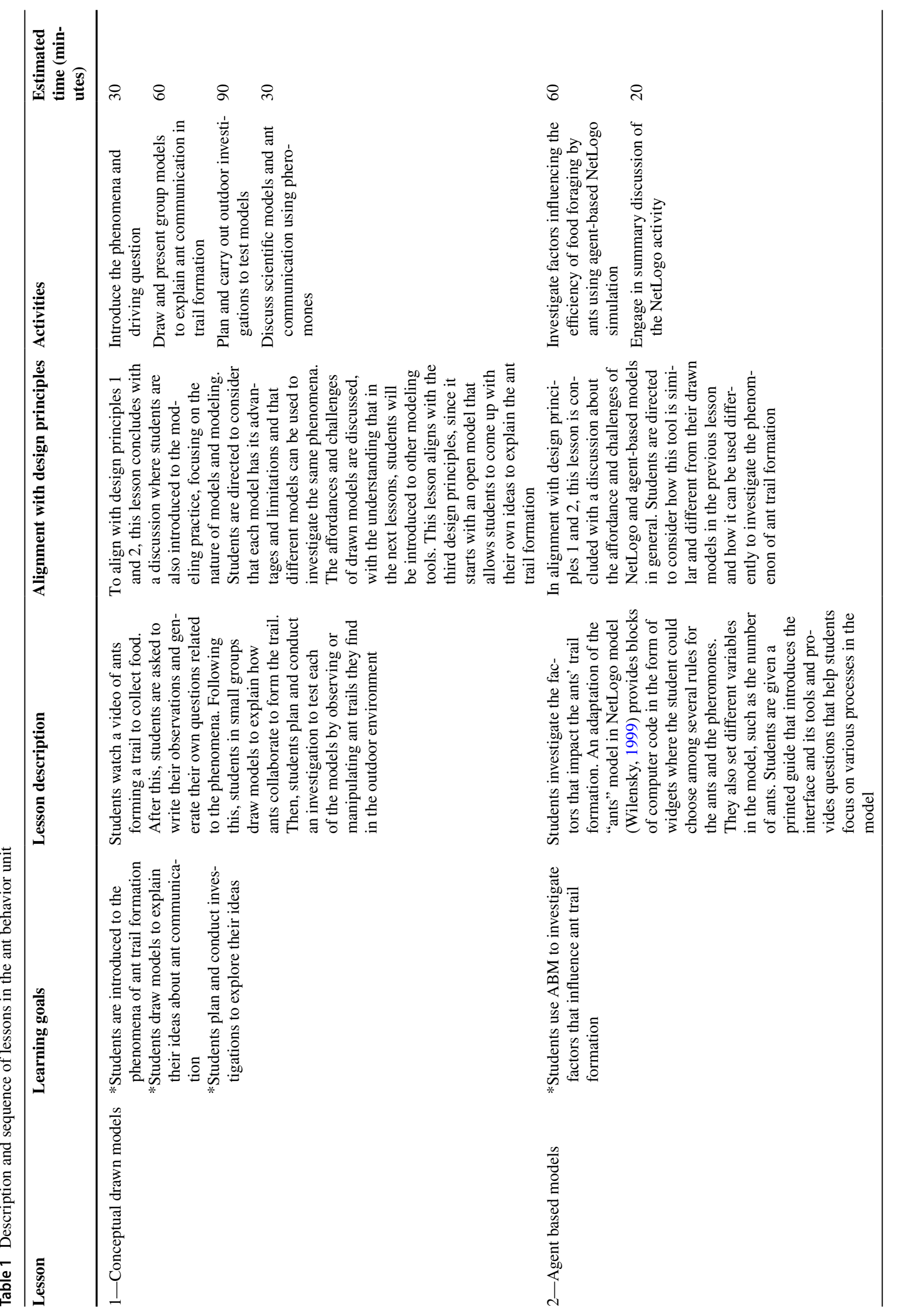




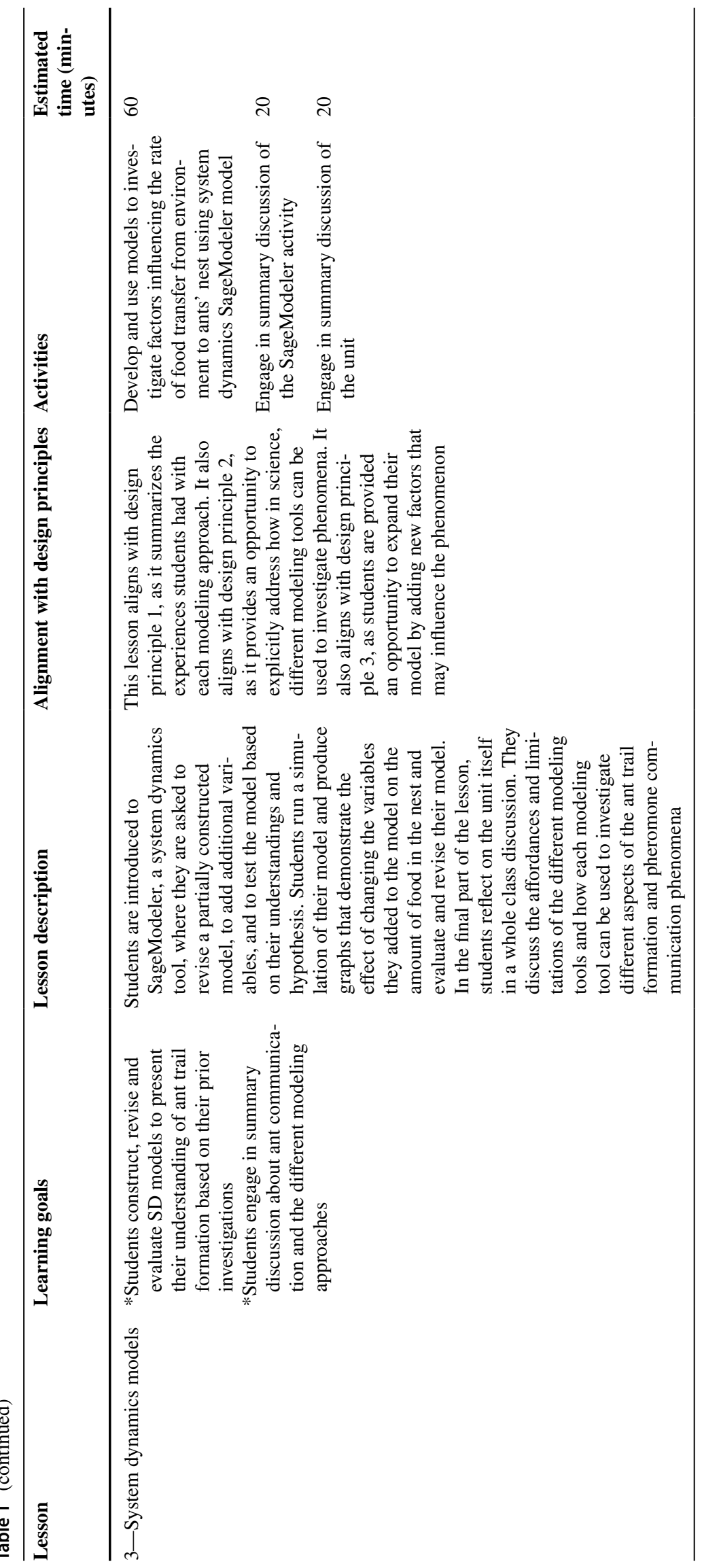


observational notes were examined by the authors and used to describe the enactment of the unit and to capture students' attitudes toward and using the modeling tools in the unit. Specific relevant parts of the whole-class discussion recordings during the lessons were transcribed and translated to English.

\section{Pre- and Post-unit Questionnaires}

Pen and paper questionnaires were administered before the beginning of the first lesson and following the last lesson of the unit. Twenty-three students filled out both the pre- and post-unit questionnaires and were included in the analysis.

Since there are no existing items that specifically explore students' conceptual understanding about ants' chemical communication, the authors developed two open-ended questions that were used in the pre- and post-unit questionnaires. The first question was "How do the ants create the trail?." Students' responses were coded and classified into emerging categories by two of the authors in an iterative process until full consensus was reached. Emerging categories are detailed in Table 2. The second question was "How do ants communicate?" Again, student responses were classified into emerging categories by two of the authors in an iterative process until full consensus was reached. Some responses were classified into more than one category. The description of emerging categories is provided in Table 3.
To investigate possible changes in students' metamodeling knowledge, pre- and post-unit questionnaires included the following open-ended questions: (i) What is the scientific model? and (ii) What do scientists use models for? These questions were based on questionnaires that were developed, validated, and used in other studies (e.g., Grosslight et al. 1991; Gobert and Discenna, 1997; Sins et al., 2009). Student responses for both questions were independently classified into combined emerging categories by two of the authors. Some responses were classified into more than one category. Several iterative cycles of categories revision were carried out by the authors until full consensus was reached. Inter-rater reliability for all student responses was calculated using Cohen's kappa coefficient. A high reliability score was reached $(k[\mathrm{SE}]=0.664[0.078])$. Emerging categories are detailed in Table 4.

\section{Teacher Interview}

The teacher of the class, Dina, was interviewed three months following the enactment of the unit. In this semi-structured interview, the teacher was asked questions regarding the students' experience in learning about models and using technology tools in science class, her and the students' experiences during the lessons and using the modeling tools, and the advantages and disadvantages of using the modeling tools in the unit. The interview was audio recorded, and

Table 2 Emerging categories of students' conceptual understanding of ant communication

\begin{tabular}{|c|c|c|}
\hline Category & Description & Example \\
\hline Physical construction & Ants physically construct the trail and walk through it & $\begin{array}{l}\text { "I think the ants create the trail by digging in the ground." } \\
\text { (Student \#9, pre-questionnaire) }\end{array}$ \\
\hline Chemical trace & $\begin{array}{l}\text { Ants that find food secrete pheromones to recruit other } \\
\text { ants from the nest to the food source }\end{array}$ & $\begin{array}{l}\text { "The ants smell the pheromone that other ants release on the } \\
\text { trails, follow it and reach the food." (Student \#3, post- } \\
\text { questionnaire) }\end{array}$ \\
\hline Individual follow & Ants follow each other as they forage for food & $\begin{array}{l}\text { "Following each other until there is a convoy." (Student \#16, } \\
\text { post-questionnaire) }\end{array}$ \\
\hline Path description & $\begin{array}{l}\text { Ants that find food return to the nest to recruit other ants } \\
\text { by communicating the location of the food (similar to } \\
\text { bee dance in hive) }\end{array}$ & Evident in students' drawn models (see Fig. 3) \\
\hline Other & Not relevant or not clear responses & $\begin{array}{l}\text { "I think ants can just handle the condition of the soil." (Stu- } \\
\text { dent \#11, pre-questionnaire) }\end{array}$ \\
\hline
\end{tabular}

Table 3 Classification of student responses to the question "how do ants communicate?" (Words relevant to the category are underlined by authors.)

\begin{tabular}{ll}
\hline Category & Example \\
\hline Pheromones or smell & "I think ants communicate with each other using pheromones." (Student \#2, post-questionnaire) \\
Antenna & "I think ants communicate by using antennas." (Student \#14, post-questionnaire) \\
Language or sound & "Ants has a unique language of their own." (Student \#11, pre-questionnaire) \\
Gestures or motion & "Smell, motion, like bees." (Student \#22, pre-questionnaire) \\
Physical contact & "I think ants communicate with each other by contact." (Student \#7, post-questionnaire) \\
\hline
\end{tabular}


Table 4 Classification of student concepts about what scientific models are used for, as derived from responses to question 1 ("what is a scientific model?") and question 2 ("what do scientists use models for?")

\begin{tabular}{|c|c|c|}
\hline Category & Description & Example \\
\hline Represent & Used to represent a scientific idea or experiment results & $\begin{array}{l}\text { "I think a scientific model is a model that represent and transfer } \\
\text { knowledge related to a scientific topic." (question 1, student \#7, pre- } \\
\text { questionnaire) }\end{array}$ \\
\hline Explain & Used to explain a phenomenon or an idea & $\begin{array}{l}\text { "I think a scientific model is something (drawing, object etc.) that pre- } \\
\text { sents a certain phenomenon and explains it." (question 1, student \#13, } \\
\text { post-questionnaire) }\end{array}$ \\
\hline Investigate & Used to investigate or explore a phenomenon & $\begin{array}{l}\text { "Scientists use models to see what effects what, what can happen } \\
\text { (options) or to try to see what is happening." (question 2, student \#10, } \\
\text { post-questionnaire) }\end{array}$ \\
\hline Understand & Used to understand a scientific idea or principle & $\begin{array}{l}\text { "Scientific model is something that demonstrates a certain phenomenon } \\
\text { in order to develop understanding." (question 1, student \#3, post- } \\
\text { questionnaire) }\end{array}$ \\
\hline Learn & Used to learn scientific knowledge & $\begin{array}{l}\text { "[scientists use models] To answer people needs to investigate and learn } \\
\text { new things." (question 2, student \#6, pre-questionnaire) }\end{array}$ \\
\hline Predict & Used to predict possible outcome of changes in a system & $\begin{array}{l}\text { "I think a scientific model is a tool for predicting or demonstrating a } \\
\text { certain research." (question 1, student } \# 19 \text {, pre-questionnaire) }\end{array}$ \\
\hline
\end{tabular}

several relevant parts were transcribed and presented in the results.

\section{Results}

\section{Students' Engagement with the Different Modeling Approaches}

To investigate the first research question, how students engaged with the different modeling approaches integrated in the unit, we present results from the following data sources: (i) student groups' drawn models; (ii) students' written responses in the ABM worksheets, indicating the development of students' understanding of complexity and the content; and (iii) students' submitted SD models, representing the development of their understanding of modeling and modeling abilities.

In their drawn models, multiple different ideas about trail formation were expressed. Two groups included a centralized control, noting an ant that finds the food and leads the others to it. Other groups had a less clear drawn mechanism for how the trail forms. Five out of the six groups included smell as a communication signal or as part of the signal. Another group had a signal similar to radio waves. Sensing organs were either not specified or noted as the antenna. There was no mention of critical mass of ants needed for the trail to emerge; a single ant trail seemed to be enough to draw others. There was no representation of evaporation or strength of smell in any of the drawn models. However, one of the models did include a parameter for how much food there was at the source and information about how many ants would be needed to move it. Several groups added a written explanation to their drawn models. One group suggested that there is one ant that recruits other ants by transmitting a signal from the food source (Fig. 1a), while other groups suggested the ants follow each other to the food source based on the pheromone trail created by the ant that found the food source on its way back to the nest (e.g., Fig. 1 b and c). Due to time limitations, the lesson did not include planning and carrying out the outdoor investigation. Instead, it was performed by the students as a homework assignment. The other lessons were carried out in full alignment with the curriculum.

\section{Agent-Based Modeling}

In the second lesson, students were introduced to the ant agent-based model. They worked in groups of two or three and investigated how ant trails form and how factors affect the rate food is transferred to the nest. An analysis of students' worksheets showed that five out of the 12 groups noticed how increasing the ants' randomness in motion increases their ability to find food; three groups saw a phase change in the system, when enough pheromone was dropped to form a stable path; and most of the groups shifted from single- to multi-step explanations. Students were asked to examine the effect of increased randomness in the ants' motion on the collective foraging pattern. This is a challenging concept, as counterintuitively increasing the ants' randomness in motion actually stabilizes the system. Two groups addressed this challenge, each holding an opposite view. One group saw that going in straight lines with no random "wiggle" resulted in less efficient foraging because "When the ant goes straight, they don't have an option to find food in other directions, and that slows her down." The 
other group thought that moving in straight lines was more efficient and would get them to the food piles faster. It is interesting to note that neither group shifted from the single ant's efficiency in finding food to efficiency of the ants as a group.

One pair of students transitioned during the activity through three successively sophisticated explanations of the ants' trail: (1) "[The more ants] the greater the rate of transferring food to the nest, until a certain limit," the limit showing the idea of saturation; to a rich description of individual ants' behaviors: (2) "The ant comes out of the nest to share the food reservoir. She takes it and returns to the nest, while passing the ants who are still on the way and staying on the curving (zigzag) pheromone trail"; to a highly connected micro- and macro-level explanation that combines several variables mechanistically and includes ideas of randomness and critical mass: (3) "As the rate of pheromone release increases, more ants bring more food. When there is no pheromone, the ants behave randomly. As the number of ants goes up, so does the food increase their clustering into groups with the pheromone." It is interesting to see their sophisticated interactive view of the food sources causing the ants to cluster.

Students were asked, before approaching the computational ABM model, what will happen to the rate at which food is transferred to the ant nest when there are more ants. All student groups answered that the rate of food transfer would increase. The other six groups that filled out the worksheet wrote intermittently, mostly as a result of limited time. Six groups focused on the number of ants transferring the food ("We think the rate of transferring the food to the nest would be much faster because if there are more ants, there are also more ants to bring the food"), and two groups focused on the ants not only transferring but also finding (foraging) for the food ("We think that the rate at which food is transferred to the nest would increase, because there would be more ants to move it, find new food and bring it to the nest"). One group thought there was a limit above which increasing the number of ants would not increase the rate of transfer, alluding to an unexplained saturation: "Faster when there are more ants, up to a limit."

When asked to describe what is happening in the model, three groups responded. Each group saw very different things. They all saw the two distinct roles of finding food and transporting it. They all noted the pheromones emitted by the ants once they found food and headed home. From here, the descriptions diverged. One group ended the story at this point, ignoring the trail formation and its attraction for other ants: "When the ants find food, they magically know the way to their home and distribute pheromones on the way." Another group noted that the pheromones attract more ants "...until an ant finds food, she then emits the pheromone that helps other ants find food...." The third group could see the whole process:

The ants leave the nest, and search for food. When they find, they emit pheromones, that cause more ants to leave the nest in the direction of the food - that's where the pheromones were emitted. The ants take the food to the next, return and take more food, and so on... It's important to note that the food the ants find first is closer to the next, and that's why they finish it before they go to take food from the other sources.

Towards the end of the worksheet, students were asked to conclude from the activity. This item encouraged much writing, as the students tried to pull the different parts together, and at times rose above their previous conclusions. An example of the first: "The rate at which pheromone is released... Their form of walking... and the number of ants." An example of abstraction happened for two groups who redefined the role of the food as causing the ants to coordinate their steps in foraging: "The more ants there were, the more the pheromones could help the ants become united by the food." One pair saw the food as "crystallizing" groups: "As the number of ants increased, so did the number of pheromones and their clustering into groups by the food." Two groups noticed phase change or a threshold in the system - that only having enough ants would make a trail happen: “... only above 60 ants, there was a path."

To conclude, most groups shifted from simple to multistep and mechanistic explanations. Some began incorporating randomness into their descriptions as well as thresholds and phase change.

\section{System Dynamics Modeling}

In the SD modeling lesson, students engaged in using the online modeling tool SageModeler to build and revise their models and to investigate variables affecting the transfer rate of food from the environment to the ants' nest. Since students had only one lesson to learn how to use the modeling tool, to construct their models and to run a simulation, they were provided with a partially built model and were guided to connect several variables ("ant speed," "number of ants," and "pheromone evaporation rate") to the node of "rate of food transfer" (see Fig. 3).

Eleven groups produced a final model at the end of the lesson (a total of 23 students), with one more group that produced a model but did not send a shared link to their model. All other eleven groups produced runnable models that included all initially given variables. Seven of the groups added additional variables that were not included in the original model, such as "Temperature" or "Distance from the nest." 
Most groups were able to understand how to develop and use their SD models to investigate the factors influencing the rate of food transfer to the ants' nest, as was evident in their final models that included all the given variables. For example, one group produced sophisticated models using SageModeler (Fig. 4). They identified the correct model question/goal: "Investigate what effect the amount of food in the ants' nest and how." All the provided variables were correctly connected to the main model and all relationships between variables were accurately defined. The explanations for each relationship, as provided by the students in the explanation box, were causal and included some additional cause-and-effect elements. For example, to explain the decreasing effect of pheromone evaporation rate of rate of food transfer, students wrote: "When the pheromone evaporation rate is higher, so is the ant trail more blurry/ unclear to the ants and it is more difficult for the ants to reach the food." These students also included an additional variable to the model, "Temperature of the environment," which had an increasing effect on the pheromone evaporation rate. This relationship was also explained with appropriate causal reasoning: "The higher the temperature, so does the pheromone particles diffusion in the air space increases in speed, and the evaporation rate increases." Finally, these students were also able to run an initial simulation of their model, as seen by the line in the two stocks variables, "Amount of food in the environment" and "Amount of food in the nest."

In the whole class discussion following the SageModeler activity, some students identified that the goal of the model was to investigate what are the factors influencing the rate of food transfer from the environment to the nest by the ants. They mentioned the dynamic nature of the model as manifested by the interaction between the variables ("There are all kinds of parameters [in the model] that are all connected to each other and every parameter has some connection to another one"). Several students also discussed the changeable and open nature of the tool, where they can add and change any variable they think of. Some students also mentioned the complexity of using the tool: that it took some practice to understand how it works and that running the simulation is not very visual. In the following section, a detailed example from the two focus groups is presented.

\section{Students' Conceptual Understanding and Metamodeling Knowledge}

Results indicate that students' knowledge about ant communication developed during the lessons.

\section{Conceptual Understanding About Ant Trail Formation and Communication}

In response to the first question about ant trail formation, most students in the pre-questionnaire suggested that the trail is physically formed by the ants. However, in the postquestionnaire, most students provided the correct answer, in which the ants that find the food source secrete a pheromone trail on its way back to the nest to recruit other ants (Fig. 5).

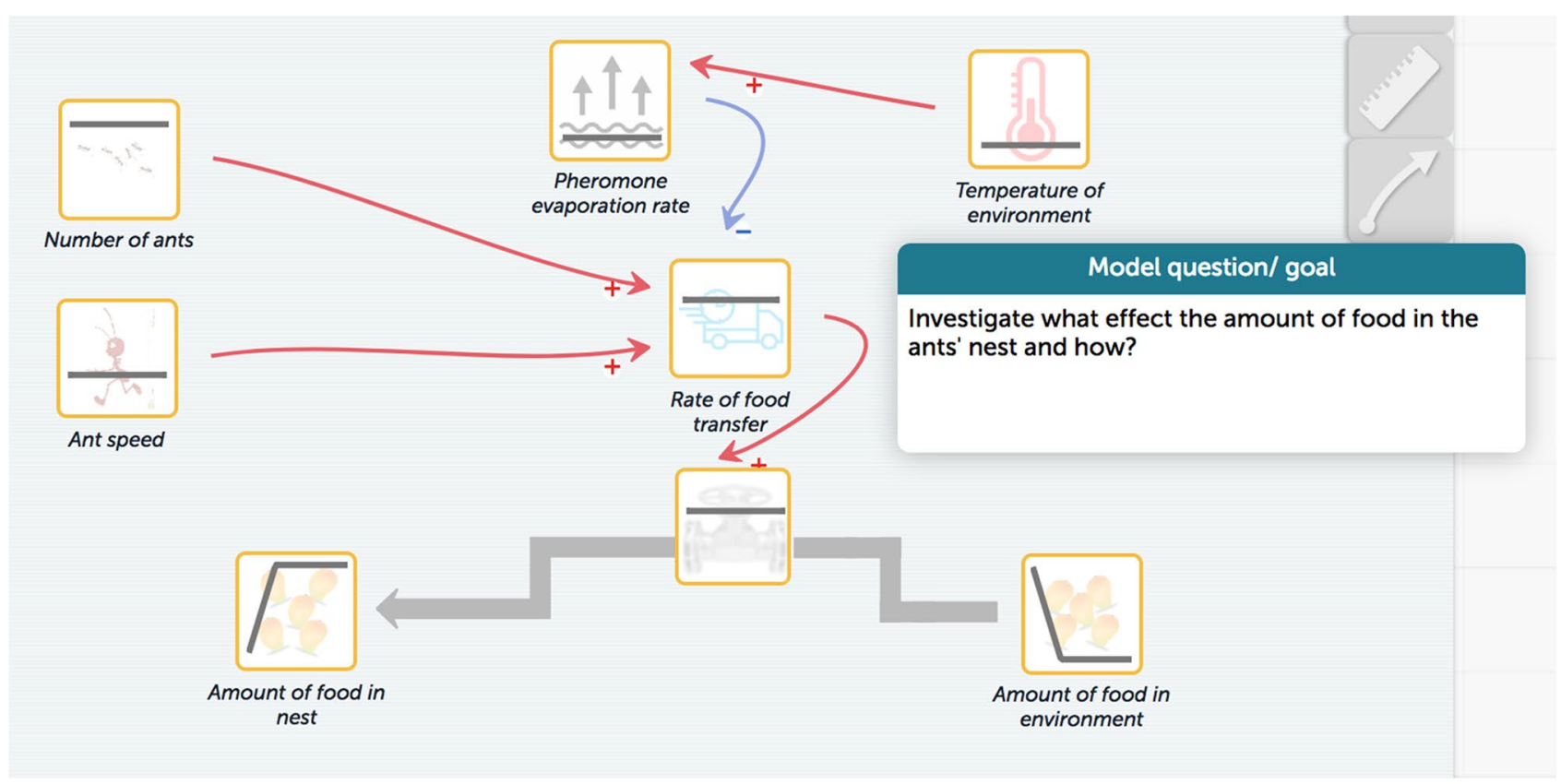

Fig. 4 Example of one group's SageModeler final model (translated from the Hebrew version). Red arrows represent an increasing effect; blue arrow represent a decreasing effect. Gray arrow represents the flow of food from the environment to the nest 
It is interesting to note that although several student groups described how ants recruit other ants to the food source by describing the location to them (similar to the bee's dance) in their drawn models, this was not found in any of the students' written responses in the pre- or post-questionnaire. In response to the second question about ant communication, there was an increase in the percentage of students mentioning the secretion of pheromones, using antenna and physical contact following the enactment of the unit, while there was a decrease in the percentage of students mentioning communication by gestures or motion (Fig. 6).

Students' views about how the lessons helped them learn about ant communication by modeling were mostly positive. During the whole class summary discussion, students mentioned that all models they used helped them explain the phenomenon of ants transferring food to the nest. Students mentioned that using the different modeling tools helped them better understand the concepts related to ant behavior. For example, one student said, "This is how all of our materials should be taught. I was able to understand much more that I usually able to." Another student added: "This [the models] allows us to understand the effect of one variable on another variable ... It is much easier for me to learn like this and I feel I understood it." Students noted that learning using the computers was an exciting experience for them, different from typical lessons, because of the visual and interactive nature of the tools. Students claimed that the computational tools allowed them to play around with the models, which
Fig. 5 Classification and number of student responses to the question "How do ants create the trail?" (Number of student responses $=23$ )

Fig. 6 Categories and percentage of student responses to the question "how do ants communicate?" (Number of students $=23$ )
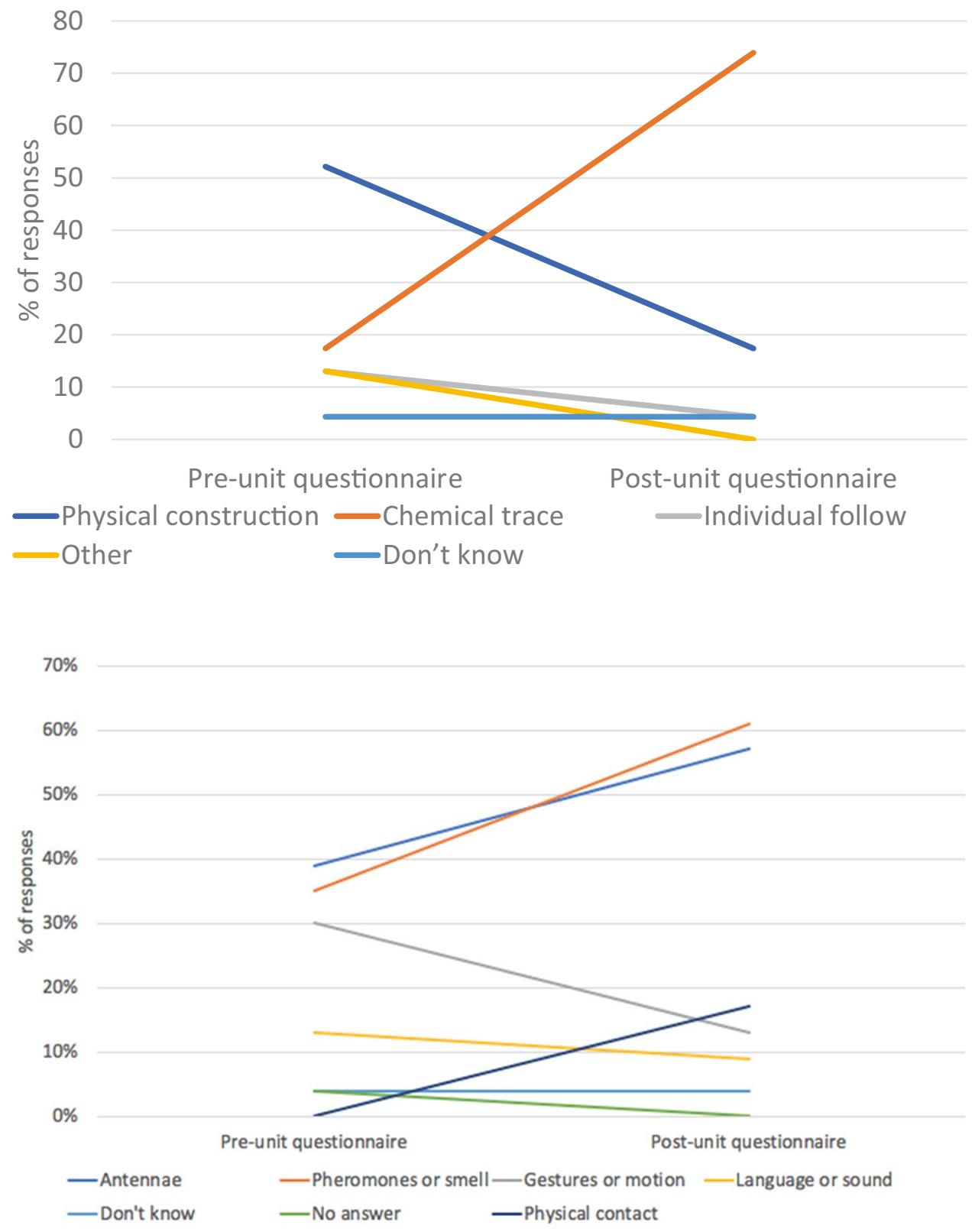
helped them to better understand the topic and was more enjoyable.

In her interview, the teacher supported these issues, mentioning that although some students faced difficulties when using the modeling tools, it is still a very important to competence that should be integrated in science lessons. She also discussed the technical and logistical challenges she faces as a teacher in the school when it comes to using computers, since there are not many of them available and not enough staff can support her in using technology.

\section{Metamodeling Knowledge About Models and Modeling}

As seen in Fig. 7, the largest increase was in the percentage of students mentioning that models are tools used to investigate and explore phenomena. There was a small decrease in the percentage of students mentioning that models are used to explain phenomena or that models are tools for learning new ideas in the post-unit questionnaire. No change was found in the percentage of students mentioning that models are used to understand the concepts that were learned.

In the whole class discussion, students pointed out that all the models included parameters that they could change, manipulate, and investigate. Students discussed some of the differences between the modeling tools: the complexity of each model, how well they can express their ideas, the visual and dynamic nature of each model, and how structured or open each model was.

\section{Discussion}

This study describes the design and development of an innovative middle school curricular unit that integrates different modeling approaches to investigate complex phenomena and provides results from an initial implementation of the unit in one classroom. The three modeling approaches-conceptual models, ABM, and SD-provided students with opportunities to share and test their ideas about ants' collective behavior when forming the trail to transfer food to the nest and to investigate the factors that influence the efficiency of ant food foraging. Since only few studies have been conducted on designing curricular materials that integrate different modeling approaches when investigating complex phenomena, this study provides insights about the advantages and limitations of one such intervention that aims to promote students' conceptual understanding, system thinking, and modeling practice.

Three main design principles, based on the literature about models and modeling and design considerations for supporting students in software-based inquiry (Quintana et al., 2004), served as the basis for the unit design. While the first and third principles (engagement with several modeling approaches and hourglass modeling sequence) were appropriately implemented in the classroom enactment, we found that students had limited experience with the second design principle (Explicit consideration of affordances and constraints of each modeling approach), mostly due to time limitations and the considerable efforts that were placed on learning each of the modeling tools. We suggest that teachers should be directed to place more attention on the impact
Fig. 7 Categories and percentage of student epistemic knowledge about what models are used for (Number of students $=23$ )

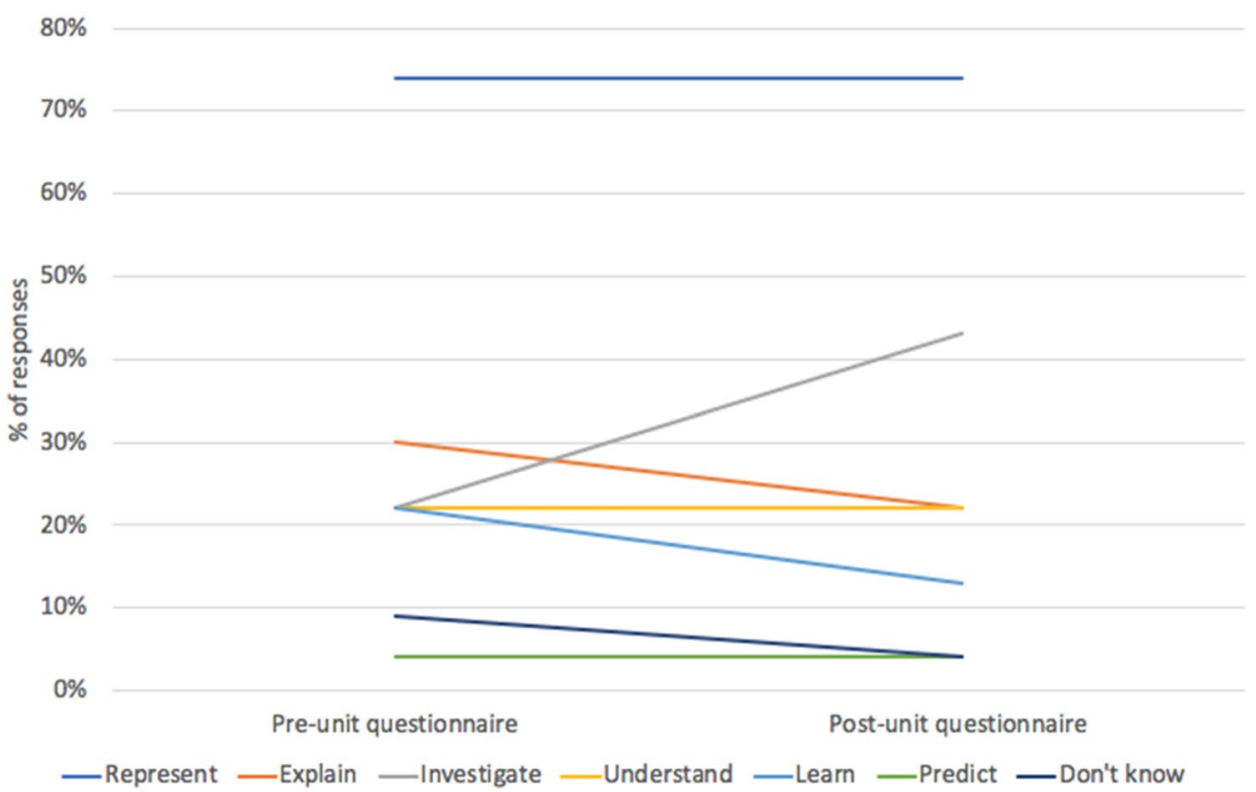


these discussions have on students' modeling knowledge. Also, we suggest that future enactments of the ant communication will place more focus on the integration of the ABM and SD models, for example, by emphasizing that findings from $\mathrm{ABM}$ simulations should be considered and evaluated using the SD models.

Results indicated that students engaged with some core aspects of modeling practice, such as constructing, using, evaluating, and revising models, as recommended by Schwarz and colleagues (2009). In the lessons, students developed and revised their models and used them to run simulations to investigate the effect of several factors on the efficiency of ants' tail formation. We hypothesize that the collaborative nature of the activities in the unit was an important factor that pushed students to fully engage with the modeling tools, since in all lessons, students worked in small groups to develop and use their models and shared their models with their peers to receive feedback. This aligns with the findings of Wilkerson-Jerde et al. (2015) regarding the contribution of collaborative meaning-making when engaging in modeling with multiple representations. However, further investigation of students' interactions when collaborating on their models is required to support this view and to gain more in-depth understanding of this process.

Students required technical and conceptual support when using the computational modeling tools, since this was a new practice for them and they did not have many opportunities to use such technology tools in school prior to the intervention. As described by Wilkerson et al. (2018), students in our enactment successfully engaged in both the epistemic forms and the epistemic games that are necessary for meaningful sense-making in each of the modeling approaches. Time was one of the main limiting factors during the lessons, resulting in limited opportunities to engage students in broader discussions about the affordances and constraints of each modeling approach. We believe that integrating several modeling approaches in one unit holds a strong promise to promote middle school students' learning, provided they are given appropriate scaffolds and time to engage with each of the modeling approaches and to discuss the affordances and limitations of each.

We found that the students' knowledge of ant communication increased following learning the unit. We also found some gains in students' metamodeling knowledge about models as tools for investigating phenomena. However, no significant changes occurred in students' perception of models as tools for explaining and predicting phenomena. The relatively minor changes in students' metamodeling knowledge were expected, as previous studies indicated that changes in metamodeling knowledge require deep learning processes, and young students can demonstrate temporary changes in the metamodeling knowledge in specific situational context (Grosslight et al., 1991; Krell and Krüger,
2017; Schwarz and White, 2005). These findings suggest that integrating different modeling approaches in one unit can elevate students' learning of conceptual content knowledge with some small effect on their metamodeling knowledge. The limited progression in students' metamodeling knowledge about the nature of scientific models was most likely due to the limited time they had to fully engage with the different models and to explicitly discuss the affordances and constraints of each modeling approach. Since these were key aspects of our design principles, it is suggested that students should be provided with sufficient time to engage with the modeling approaches and to include explicit discussions about the advantages and limitations of each modeling approach.

Stroup and Wilensky (2014) suggested the "embedded complementarity" framework to bridge between reasoning through agent-based and system dynamics approaches to understand complex systems. They claim that both forms of reasoning share certain features, such as the dynamic description of a system, so that the timeline provides a shared representation. Eilam and Reisfeld (2017) further advanced the issue of integrating SD and ABM, showing that a year-long intervention with 9th grade students contributed to their content learning and understanding of complex systems. Similarly, Wilkerson-Jerde et al., (2015) stated that: "Generating drawings, animations, and simulations of a particular scientific phenomenon can engage learners with complementary aspects of scientific modeling (such as model development, refinement, testing, and use) and disciplinary content." (p. 399). We view our study as further support for promoting the pedagogy of integrating several modeling approaches when investigating complex systems, not only in the context of computational simulations but also as an approach that engages students in several modeling tools, including their own drawn conceptual models, in order to build their understanding of models and modeling.

This study has several limitations. First, it was carried out in one (honors) middle school classroom. Therefore, findings should not be generalized to all middle school science classrooms and further studies are required to explore the reproducibility and generalizability of our findings. Second, the intervention was short and limited in scope. Also, the teacher in this study received limited amount of professional development time to prepare for teaching the unit and should be more involved in setting up the unit and lessons in order to adapt them to her specific classes. Therefore, future enactments will include further in-depth examination of students' modeling process and their engagement with the integration of the modeling approaches. We also plan to examine the possible impact of the specific modeling approaches sequence on students' learning outcomes.

This study contributes to our understanding of how integrating different modeling approaches can promote students' 
conceptual understanding and metamodeling knowledge. We identified several of the affordances and constraints that influence students' engagement with the computational modeling approaches as they investigate complex phenomena, which is important for curricula development and advancing students' science learning.

Funding Open Access funding enabled and organized by Projekt DEAL.

\section{Compliance with Ethical Standards}

Ethical Approval We declare full compliance with the required ethical standards in this study. All participants of this study provided informed written parental consent and personal verbal consent under the research institute IRB regulations.

Conflict of Interest The authors declare that they have no conflict of interest.

Informed Consent Statement All authors contributed to the study conception and design. Material preparation, data collection, and analysis were performed by Tom Bielik, Ravit Golan Duncan, and Sharona T. Levy. The first draft of the manuscript was written by Tom Bielik, and all authors commented on previous versions of the manuscript. All authors read and approved the final manuscript.

Open Access This article is licensed under a Creative Commons Attribution 4.0 International License, which permits use, sharing, adaptation, distribution and reproduction in any medium or format, as long as you give appropriate credit to the original author(s) and the source, provide a link to the Creative Commons licence, and indicate if changes were made. The images or other third party material in this article are included in the article's Creative Commons licence, unless indicated otherwise in a credit line to the material. If material is not included in the article's Creative Commons licence and your intended use is not permitted by statutory regulation or exceeds the permitted use, you will need to obtain permission directly from the copyright holder. To view a copy of this licence, visit http://creativecommons.org/licenses/by/4.0/.

\section{Appendix}

\section{Appendix 1. Description of Unit Lessons}

The unit was designed based on the features of project-based learning curriculum (Krajcik and Blumenfeld 2005), starting by introducing students to the driving question ("How do ants create the trail to forage for food?") and to the anchoring phenomena of ant trail. This was followed by student-centered collaborative investigations to explain the phenomenon and to answer the driving question using scientific practices (such as planning and carrying out investigations, developing and using models, engaging in argument from evidence), and producing artifacts in the form of drawn and computational models.
Lesson one. In the first lesson, students were introduced to the phenomena by watching a video of ants forming a trail to collect food. From this video, students were asked to write their observations and generate their own questions related to the phenomena. Following this, students in small groups drew a model to explain how ants collaborate to form the trail. Students were expected to come up with three main models: (i) centralized system where ants are directed by central agents to follow the trails, (ii) emergent system in which each ant follows the ant in front of it, and (iii) emergent system where ants follow some signals in the path to the food source. After this, students planed an investigation to test each of the models by observing or manipulating ant trails they find in the outdoor environment. By the end of this lesson, based on their investigations, students figured out that ants mostly communicate using pheromones that are picked up by their antenna and that there is no centralized system that directs them where to go; it is rather a phenomenon that emerges from a set of collective behavior and patterns that ants follow.

To align with design principles 1 and 2, this lesson concluded with a discussion in which students were introduced to the modeling practice, focusing on the nature of models and modeling. From this discussion, students were directed to consider that each model has its advantages and limitations and that different models can be used to investigate the same phenomena. The affordances and challenges of drawn models were discussed. This lesson aligns with the third design principles, since it started with an open model that allows students to come up with their own ideas to explain the ant trail formation. Only in the second lesson that students were directed to focus on a specific set of factors that may influence the efficiency of food transport and pheromone communication.

Lesson two. After constructing their drawn conceptual models and discussing them, the students in the second lesson assembled their own models and investigated the factors that impact the ants' system. An adaptation of the ant model in NetLogo model (Wilensky 1999) provided blocks of computer code in the form of widgets where the student could choose among several rules for the ants and the pheromones. This was not a full construction of the model, as it was based on limited choices, and because the students quickly centered on the correct model and explored it, rather than dealing with its structure. They also set different variables in the model, such as the number of ants. Students were given a printed guide that introduced the interface and its tools and were provided questions that helped the students to focus on various processes in the model. The students then designed their own study and explored the model. Some of these challenges were designed to help students attend to the efficiency of food collection in different conditions.

In alignment with design principles 1 and 2, this lesson concluded with a discussion about the affordance and challenges 
of NetLogo and agent-based models in general. Students were directed to consider how this tool is similar and different from their drawn models in the previous lesson and how it can be used differently to investigate the phenomenon of ant trail formation.

Lesson three. In the third and final lesson, students were introduced to SageModeler, a system dynamics tool, where they were asked to revise a partially constructed model, to add additional variables, and to test the model based on their understandings and hypothesis. In the initial model provided to the students, the system included two accumulating stocks variables, "Amount of food in the environment" and "Amount of food in the nest," connected by a flow variable, "Rate of food transfer." This variable was pre-set to increase the transfer rate of food from the environment to the nest. In addition, the model included three independent variables that were not connected to the main model: "Ant speed," "Number of ants," and "Pheromone evaporation rate." These were the main variables that were investigated by the students in the previous lesson using NetLogo. Also, the model included a text box that requires students to write the question or goal of the model.

In the SageModeler activity, after a short introduction to the modeling tool, students were asked to write the question or goal of the model in the text box. Then, they were asked to connect the three independent variables to the "Rate of food transfer from environment to the nest" variable and to write an explanation to the type of relationship they defined between the variables in the relationship box. After this, students run a simulation and produce graphs that demonstrate the effect of changing the variables they added to the model on the amount of food in the nest and evaluated whether their model is correct and accurate. If it was not, they were directed to revise it and to run another simulation. At the final part of the activity, students could add other variables to the model that could affect the amount of food in the nest, such as temperature or distance between the nest and the food source. These variables were based on what they investigated in the previous lessons or on their prior knowledge, provided they have reasonable explanation or evidence. This lesson aligned with design principle 3 , as students were provided an opportunity to expand their model by adding new factors that may influence the phenomenon.

In the last part of the lesson, some of the student groups shared their models, and a whole class discussion took place to summarize and reflect on the models and the modeling tool. Students reflected on the unit itself in a whole class discussion. They discussed the affordances and limitations of the different modeling tools and how each modeling tool can be used to investigate different aspects of the ant trail formation and pheromone communication phenomena. This discussion was very important, as it summarizes the experiences students had with each modeling approach (design principle 1) and provided an opportunity to explicitly address how in science, different modeling tools can be used to investigate phenomena, based on our understanding of the model affordances and what we are trying to model (design principle 2).

\section{References}

Bar-Yam, Y. (1997). Dynamics of complex systems. Boulder, Co.

Berland, L. K., Schwarz, C. V., Krist, C., Kenyon, L., Lo, A. S., \& Reiser, B. J. (2016). Epistemologies in practice: making scientific practices meaningful for students. Journal of Research in Science Teaching, 53(7), 1082-1112.

Bielik, T., Damelin, D., \& Krajcik, J. S. (2018). Shifting the balance: Engaging students in using a modeling tool to learn about ocean acidification. EURASIA Journal of Mathematics, Science and Technology Education, 15(1), 1652.

Bielik, T., Stephens, L., Damelin, D., \& Krajcik, J. S. (2019). Designing Technology Environments to Support System Modeling Competence. In Towards a Competence-Based View on Models and Modeling in Science Education (pp. 275-290). Cham: Springer

Bielik, T., Opitz, S. T., \& Novak, A. M. (2018). Supporting Students in building and using models: Development on the quality and complexity dimensions. Education Sciences, 8(3), 149.

Chiu, M. H., \& Lin, J. W. (2019). Modeling competence in science education. Disciplinary and Interdisciplinary Science Education Research, 1(1), 1-11.

Crawford, B. A., \& Cullin, M. J. (2004). Supporting prospective teachers' conceptions of modelling in science. International Journal of Science Education, 26(11), 1379-1401.

Damelin, D., Krajcik, J. S., Mcintyre, C., \& Bielik, T. (2017). Students making systems models. Science Scope, 40(5), 78.

David Morgan, E. (2009). Trail pheromones of ants. Physiological entomology, 34(1), 1-17.

Dussutour, A., Deneubourg, J. L., \& Fourcassié, V. (2005). Amplification of individual preferences in a social context: the case of wall-following in ants. Proceedings of the Royal Society B: Biological Sciences, 272(1564), 705-714.

Eilam, B., \& Reisfeld, D. (2017). A curriculum unit for promoting complex system thinking: the case of combined system dynamics and agent based models for population growth. Journal of Advances in Education Research, 2(2).

Forrester, J. W. (1994). System dynamics, systems thinking, and soft OR. System dynamics review, 10(2-3), 245-256.

Gentner, D., \& Stevens, A. L. (Eds.). (1983). Mental models. Hillsdale, NJ: Lawrence Erlbaum.

Gilbert, J. K. (2004). Models and modelling: routes to more authentic science education. International Journal of Science \& Mathematics Education, 2(2), 115-130.

Gobert, J., \& Discenna, J. (1997). The relationship between students' epistemologies and model-based reasoning. Kalamazoo, MI: Western Michigan University, Department of Science Studies.

Gobert, J.D. \& Pallant, A. (2004). Fostering students' epistemologies of models via authentic model-based tasks. Journal of Science Education. \& Technology, 13, 7-22.

Grosslight, L., Unger, C., Jay, E., \& Smith, C. L. (1991). Understanding models and their use in science: conceptions of middle and high school students and experts. Journal of Research in Science Teaching, 28(9), 799-822.

Guerrero, G. D. C. N., Schwarz, P., \& Slinger, J. H. (2016). A recent overview of the integration of system dynamics and agent-based modelling and simulation. In 34th International Conference of the System Dynamics Society. 
Harrison, A. G., \& Treagust, D. F. (2000). A typology of school science models. International Journal of Science Education, 22(9), 1011-1026.

Israeli Ministry of Education (2016). Curricula for Elementry and Middle School Science and Technology.

Johnson-Laird, P. N. (1994). Mental models and probabilistic thinking. Cognition, 50(1-3), 189-209.

Krajcik, J. \& Blumenfeld, P. C. (2005). Project-based learning. In Sawyer, R. K. (Ed.), The Cambridge handbook of the learning sciences. Cambridge University Press.

Krell, M., \& Krüger, D. (2017). University students' meta-modelling knowledge. Research in Science \& Technological Education, 35, 261-273.

Lehrer, R., \& Schauble, L. (2006). Scientific thinking and science literacy: supporting development in learning in contexts. In W. Damon, R.M. Lerner, K.A. Renninger, \& I.E. Sigel (Eds.), Handbook of child psychology (6th ed., Vol. 4). Hoboken, NJ: John Wiley and Sons.

Louca, L. T., \& Zacharia, Z. C. (2012). Modeling-based learning in science education: cognitive, metacognitive, social, material and epistemological contributions. Educational Review, 64(4), 471-492.

National Research Council [NRC]. (2012). A framework for K-12 science education: practices, crosscutting concepts, and core ideas. Washington, DC, USA: The National Academies Press.

Nersessian, N. J. (1992). How do scientists think? Capturing the dynamics of conceptual change in science. Cognitive models of science, 15, 3-44.

Nielsen, S. S., \& Nielsen, J. A. (2019). A competence-oriented approach to models and modelling in lower secondary science education.\&nbsp; Research in Science Education, 1-29.

Nicolaou, C. T., \& Constantinou, C. P. (2014). Assessment of the modeling competence: a systematic review and synthesis of empirical research. Educational Research Review, 13, 52-73.

Passmore, C., Gouvea, J. S., \& Giere, R. (2014). Models in science and in learning science: focusing scientific practice on sense-making. In M. R. Matthews (Ed.), International handbook of research in history, philosophy and science teaching (pp. 1171-1202). Netherlands: Springer.

Penner, D. E. (2000). Chapter 1: cognition, computers, and synthetic science: building knowledge and meaning through modeling. Review of research in education, 25(1), 1-35.

Pluta, W. J., Chinn, C. A., \& Duncan, R. G. (2011). Learners' epistemic criteria for good scientific models. Journal of Research in Science Teaching, 48(5), 486-511.

Quintana, C., Reiser, B. J., Davis, E. A., Krajcik, J., Fretz, E., Duncan, R. G., et al. (2004). A scaffolding design framework for software to support science inquiry. The Journal of the Learning Sciences, 13(3), 337-386.

Rinehart, R., Duncan, R., Chinn, C., Atkins, T., \& DiBenedetti, J. (2016). Critical design decisions for successful model-based inquiry in science classrooms. International Journal of Designs for Learning, 7(2).
Russ, R. S., Scherr, R. E., Hammer, D., \& Mikeska, J. (2008). Recognizing mechanistic reasoning in student scientific inquiry: a framework for discourse analysis developed from philosophy of science. Science Education, 92(3), 499-525.

Schwarz, C. V., \& White, B. Y. (2005). Metamodeling knowledge: developing students' understanding of scientific modeling. Cognition and instruction, 23(2), 165-205.

Schwarz, C. V., Reiser, B. J., Davis, E. A., Kenyon, L., Achér, A., Fortus, D., \& Krajcik, J. (2009). Developing a learning progression for scientific modeling: making scientific modeling accessible and meaningful for learners. Journal of research in science teaching, 46(6), 632-654.

Sins, P. H., Savelsbergh, E. R., van Joolingen, W. R., \& van HoutWolters, B. H. (2009). The relation between students' epistemological understanding of computer models and their cognitive processing on a modelling task. International Journal of Science Education, 31(9), 1205-1229.

Stroup, W. M., \& Wilensky, U. (2014). On the embedded complementarity of agent-based and aggregate reasoning in students' developing understanding of dynamic systems. Technology, Knowledge and Learning, 19(1-2), 19-52.

Thompson, K., \& Reimann, P. (2010). Patterns of use of an agent-based model and a system dynamics model: the application of patterns of use and the impacts on learning outcomes. Computers \& Education, 54(2), 392-403.

Wilensky, U. (1999). NetLogo. https://ccl.northwestern.edu/netlogo/. Center for connected learning and computer-based modeling, Northwestern University, Evanston, IL.

Wilensky, U. (1997). NetLogo Ants model. Center for connected learning and computer-based modeling, Northwestern University, Evanston. IL. https://ccl.northwestern.edu/netlogo/models/Ants.

Wilkerson, M. H., Shareff, R., Laina, V., \& Gravel, B. (2018). Epistemic gameplay and discovery in computational model-based inquiry activities. Instructional Science, 46(1), 35-60.

Wilkerson-Jerde, M. H., Gravel, B. E., \& Macrander, C. A. (2015). Exploring shifts in middle school learners' modeling activity while generating drawings, animations, and computational simulations of molecular diffusion. Journal of Science Education and Technology, 24(2-3), 396-415.

Windschitl, M., Thompson, J., \& Braaten, M. (2008). Beyond the scientific method: model-based inquiry as a new paradigm of preference for school science investigations. Science Education, 92(5), 941-967.

Zimmernman, C. (2007). The development of scientific thinking skills in elementary and middle school. Developmental Review, 27(2), $172-223$.

Publisher's Note Springer Nature remains neutral with regard to jurisdictional claims in published maps and institutional affiliations.

Ravit Golan Duncan is a visiting Faculty Program Fellow at the Weizmann Institute of Science, Rehovot, Israel 